\title{
Adherence to safety practices and risks associated with health care waste management at an academic hospital, Pretoria, South Africa
}

\author{
Liziwe Lizbeth Mugivhisa, Nokuthula Dlamini, Joshua Oluwole Olowoyo
}

Department of Biology, Sefako Makgatho Health Sciences University, P.O Box 139, 0204, Pretoria, South Africa.

\begin{abstract}
Background: Adequate knowledge on hazards of healthcare waste and proper handling methods can result in its safe disposal and protection of workers and communities. The study assessed perceptions of healthcare workers on the adherence and risks associated with the practices of healthcare waste management.

Methods: A total of 126 questionnaires were administered in selected wards at an academic hospital to establish training and knowledge on legislations regarding healthcare waste and health hazards associated with such waste.

Results: Sixty nine percent $(69.0 \%)$ of participants had received training on healthcare waste handling. The highest number of cleaning staff (85.7\%) received training from work while $34.8 \%$ of the doctors also received training from work. Only $44.1 \%$ of the nurses had knowledge about policies on healthcare waste. The majority of the participants $(82.0 \%)$ had knowledge on the risks associated with handling of healthcare waste. However, only $20.0 \%$ of the participants re-capped needles after use and of these $43.5 \%$ were doctors. Most of the nurses $(64.0 \%)$ had been exposed to needle pricks.

Conclusion: Even though $82.0 \%$ of the participants believed there were enough management practices enforced with regards to the healthcare waste, it was recommended that there should be more education on the handling of healthcare waste.
\end{abstract}

Keywords: Healthcare waste; perceptions; risks; disposal, management.

DOI: https://dx.doi.org/10.4314/ahs.v20i1.52

Cite as: Mugivbisa LL, Dlamini N, Olowoyo JO. Adherence to safety practices and risks associated with health care waste management at an academic hospital, Pretoria, South Africa. Afri Health Sci. 2020;20(1):453-68. https:// dx.doi.org/ 10.4314/ahs.v20i1.52

\section{Introduction}

There have been a number of changes in the healthcare sector as a result of increasing urbanization. Provision of better healthcare services and facilities to the communities has resulted in improved and better health for all. However, healthcare facilities unavoidably produce waste which may in turn be hazardous to health in the pursuit of reducing problems related to health, and improving quality of care. ${ }^{1}$ Inappropriate management of biomedical waste resulting from healthcare facilities has also contributed to an increase in the health problems of the communities and the environment. ${ }^{2}$ Healthcare

\section{Corresponding author:}

Liziwe Lizbeth Mugivhisa, Department of Biology, Sefako Makgatho

Health Sciences University, P.O Box 139, 0204, Pretoria, South Africa. Tel: (+27) 125213959

Email: Liziwe.Mugiv hisa@smu.ac.za waste refers to the by-products of healthcare facilities. ${ }^{3}$ It includes infectious, contaminated and hazardous waste such as body parts, blood, sharps, non-sharps, pharmaceuticals, toxic chemicals radioactive substances and medical devices. ${ }^{4}$ Certain types of waste are acknowledged to be among the most potentially dangerous and hazardous wastes which arise in communities. ${ }^{5}$

The improper handling of healthcare waste can result in the main concerns and risks to environmental pollution and health effects to the patients, the public and professionals. ${ }^{6}$ Infectious healthcare waste has been reported in many studies to be responsible of transmitting more than 30 dangerous blood borne pathogens with HIV, hepatitis B and Hepatitis C being of primary significance to workers. ${ }^{7}$ In the year 2000, the World Health Organization (WHO) reported $260000 \mathrm{HIV}$ infections, 21 million hepatitis $\mathrm{B}$ and 2 million hepatitis $\mathrm{C}$ as a result of reused needles. ${ }^{7}$

Healthcare waste management is receiving more attention due to the risks to the environment and the health 
of human beings as a result of the insufficient practices of waste management. The interventions in the form of health education and promotion are needed due to the prevalence and occurrences of infections which are associated with the healthcare waste among the healthcare workers and the surrounding communities ${ }^{6}$ The process of waste management includes challenging issues such as segregation and collection, safe disposal, timely removal, safety to patients, illegal scavenging, environmental and occupational safety. ${ }^{4}$

Adequate knowledge about the hazards of the healthcare waste and the proper methods of handling healthcare waste can result in the safe disposal of healthcare waste and the protection of the communities. ${ }^{1}$ It is regarded to be an unprofessional conduct by the concerned practitioners if there is a failure to adhere to the set guidelines on the management of healthcare waste. ${ }^{8}$

Research has been done on the knowledge, awareness, practices and attitudes of healthcare workers on the healthcare waste disposal at healthcare centers., ${ }^{2,9,10,11,12}$ However to the best of our knowledge, a research gap exists on the perceptions of the healthcare workers on the adherence and risks associated with the practices associated with healthcare waste management. Hence, the study assessed the perceptions of healthcare workers on the adherence and risks associated with the practices of healthcare waste management.

\section{Methods}

The study was conducted at an academic hospital which is situated in Ga-Rankuwa, 37.0km North of Pretoria which is a capital town of South Africa. ${ }^{13}$ The hospital was originally a regional hospital but in 2011 it gained academic status which was followed by the establishment of Sefako Makgatho Health Sciences University (SMU). It is also utilized as a teaching platform for SMU and Ga-Rankuwa Nursing College. It has a total of 1652 beds and caters for a catchment area population of about 1 $200000 .^{14}$

A total number of 126 professionals who were doctors, intern doctors, nurses, sixth year medical students, laboratory staff, technologists and cleaning staff who handle healthcare waste from the departments of gynaecology, obstetrics, paediatrics, surgical, medical departments and other wards such as trauma and psychiatry were selected based on their willingness to complete the questionnaire. The sample size was calculated from the Taro method for sample size15 using the formula;

$\mathrm{n}=\mathrm{N} / 1+\mathrm{N}$ e2

where $\mathrm{n}=$ size of the sample, $\mathrm{N}=$ total population of selected area, $\mathrm{e}=$ accepted margin of error in the estimates.

The total population (total number) of the healthcare workers (doctors, intern doctors, nurses, assistant nurses, cleaning staff and sixth year medical students) in the selected wards [gynaecology, obstetrics, paediatrics, surgical, medical and others (trauma and psychiatry)] was estimated to be about 350 while the margin of error (e) was taken as $6 \%$ and the sample size was calculated as 132 . However the $10 \%$ none-response rate was used to give a final sample size of 122 participants. ${ }^{16}$

The sampling method which was used was convenience sampling based on the availability, the accessibility and the willingness of the healthcare workers to participate in the study. Only those respondents who were willing to take part in the study were considered. The sample size also included only those healthcare workers who had direct contact with the patients or with the handling of the healthcare waste such as the cleaning staff.

Data were collected by means of self-administered questionnaires which consisted of 23 questions. The questionnaires were distributed and left in the selected wards depending on the willingness of the healthcare workers to participate in the study. The completed questionnaires were collected once they had been completed by the majority of the healthcare workers. Data collected included information on demographics (gender, age, profession, level of education), training and place of training on waste disposal, knowledge on guidelines / policy / legislation regarding healthcare waste management, colour coding for waste bins, correct usage of waste bins for needles, segregation, storage and disposal of waste, recapping of needles before disposal and knowledge on risks or health hazards associated with healthcare waste. The data was then coded and descriptive statistical analysis in the form of ratios and percentages were used to analyse the data.

\section{Results}

The number of the participants from the different hospital wards is represented in Figure 1. The majority of the participants $(34.0 \%)$ were from the "other category" which included the trauma unit and psychiatry wards fol- 
lowed by the participants from the surgical and medical wards each with $21.0 \%$ of the participants. The participants from the paediatrics and gynaecology wards were
$11.0 \%$ and $7.0 \%$ respectively and the least number $(6.0 \%)$ of participants were from the obstetrics ward.

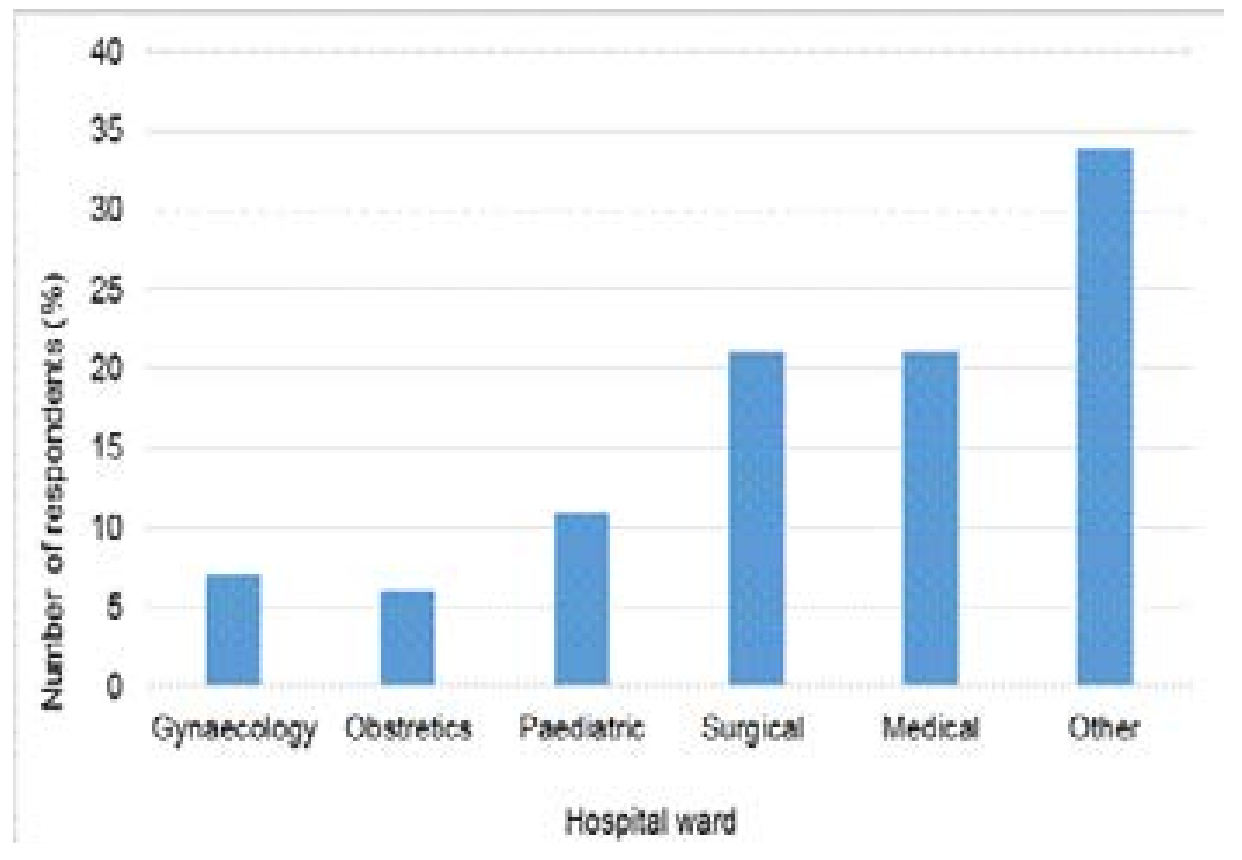

Figure 1. The number of participants from the wards at the hospital.

The age distribution of the participants as shown in Figure 2 indicates that the majority $(59 \%)$ of the participants were in the age group 26-45 years followed by the age group $46-65$ years with $26 \%$ of the participants. The least number of the participants (15\%) were less than 25 years old. According to the gender distribution of the participants as shown in Figure 3, more females (62\%) than males $(38 \%)$ took part in the study. 


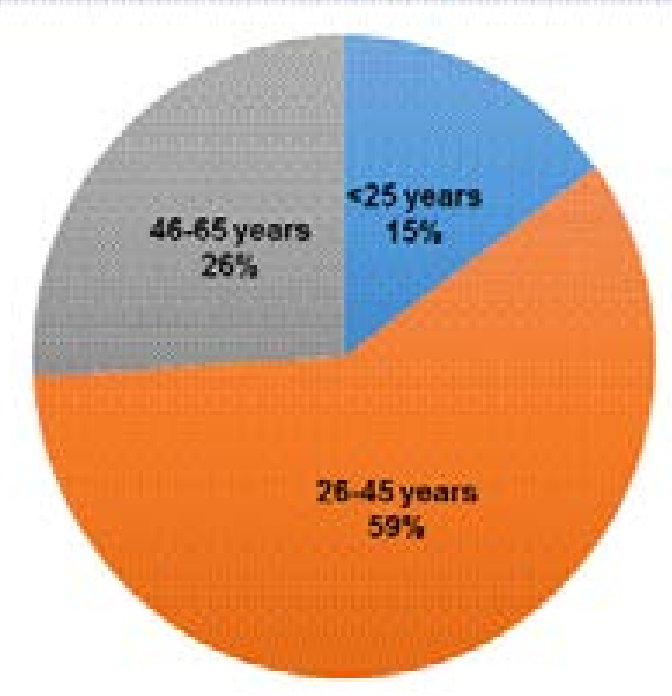

Figure 2. The age groups of the participants from the hospital.

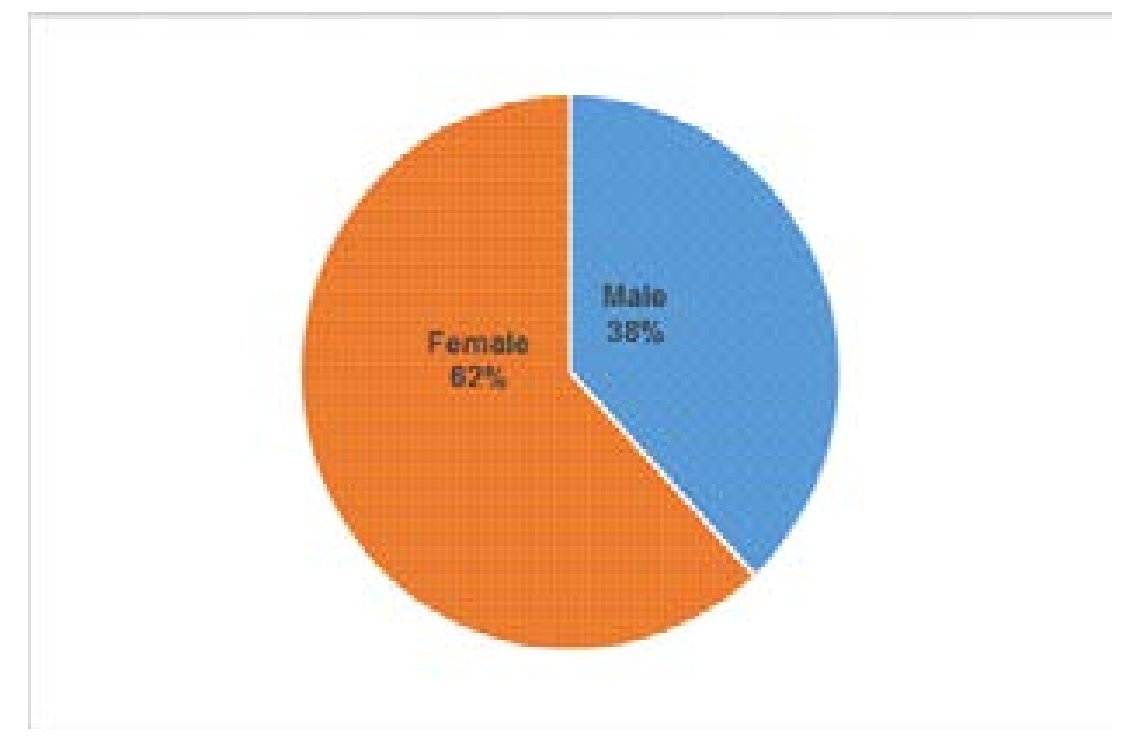

Figure 3. The gender of the participants on the perceptions on waste management practices.

Figure 4 shows that the order of the professionals who participated in the study was nurses $(29.0 \%)>$ doctors
$(20.0 \%)>$ sixth year medical students and the cleaning staff $(16.0 \%)>$ intern doctors $(9.0 \%)>$ assistant nurses $(8.0 \%)>$ laboratory technicians $(2 \%)$. 


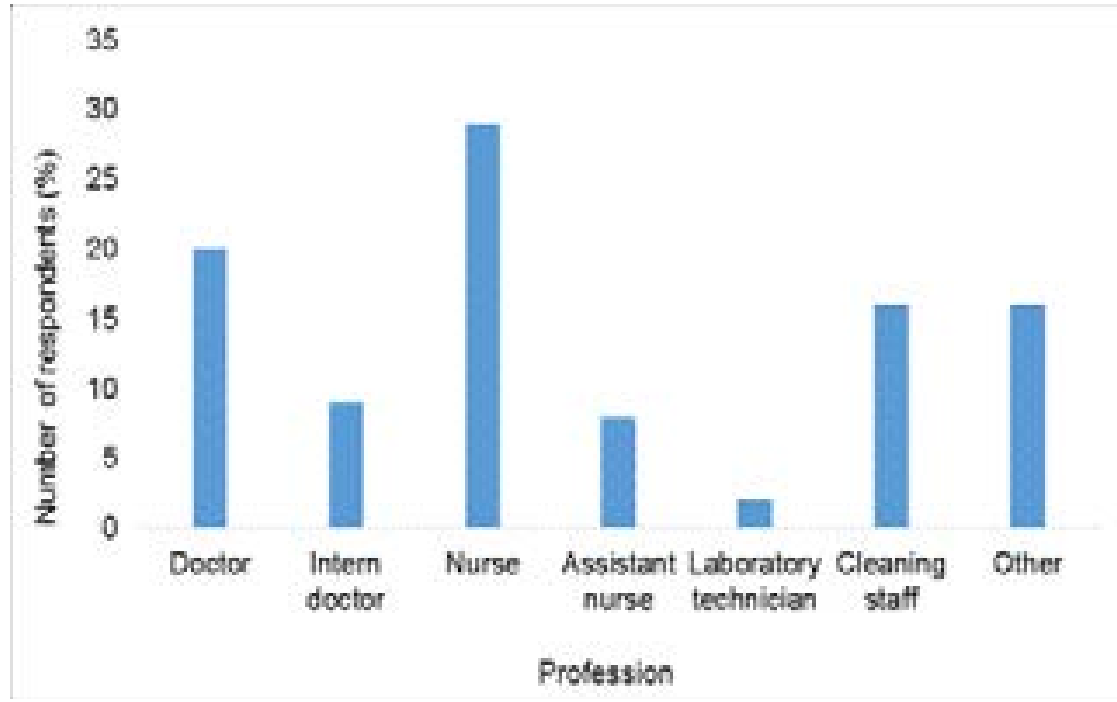

Figure 4. The profession of the participants who participated in the study.

The level of education of the participants is shown in Figure 5. Seventy six $(76.0 \%)$ of the participants had a post school qualification (12 years of school) which is three years for nurses and six years for doctors and intern doctors) followed by $17.0 \%$ who had 12 years of schooling while $4.0 \%$ of the participants had not completed 12 years of schooling. Three percent $(3 \%)$ of the participants did not indicate their level of education.

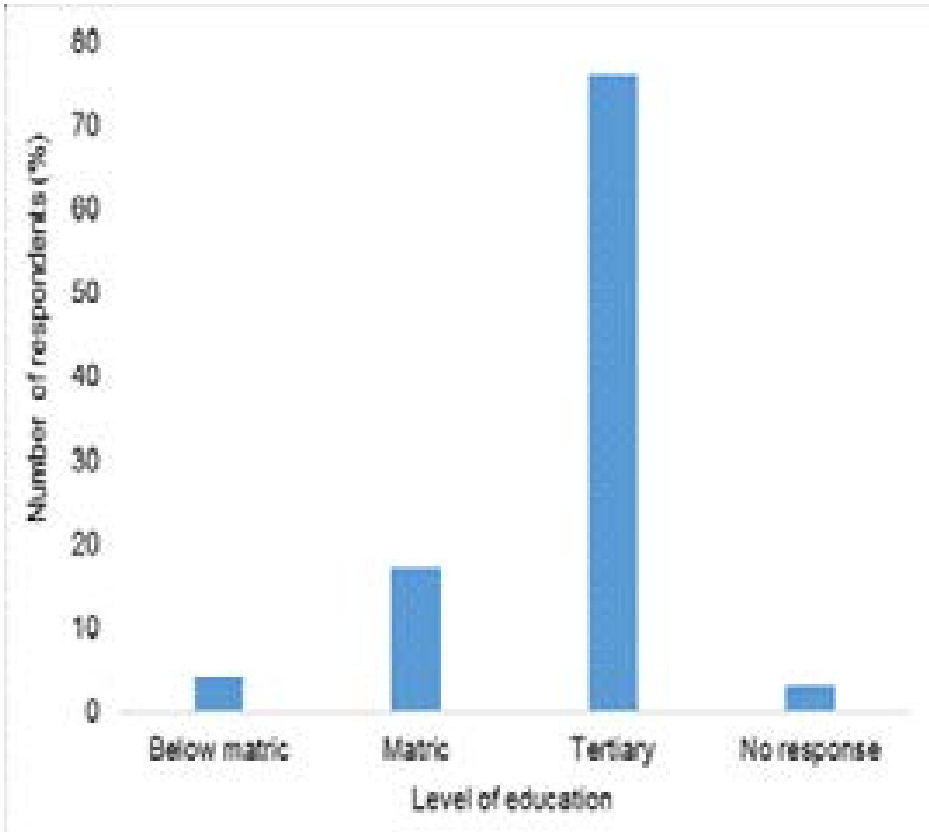

Figure 5. The level of education for the participants on the perceptions on waste management.

Figures 6 and 7 show the number of participants who had received training on how wastes should be disposed at the hospital and where training of the participants had taken place respectively. Most of the participants (69\%) indicated that they had received training while only $30 \%$ had not received any form of training. One percent (1\%) did not indicate if they had received any form of training on health care waste disposal and the majority of the participants $(37 \%$ and $36 \%$ ) had received training at work and at the institution respectively while $26 \%$ did not respond. 


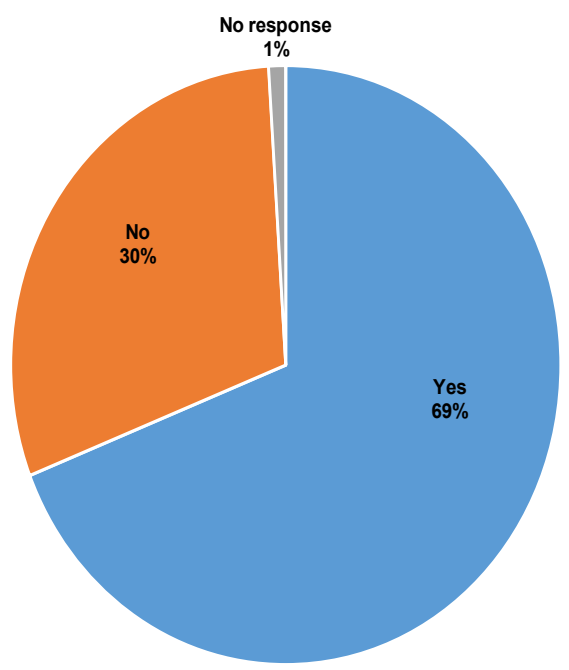

Figure 6. The number of participants who have received training on how wastes should be disposed at the hospital.

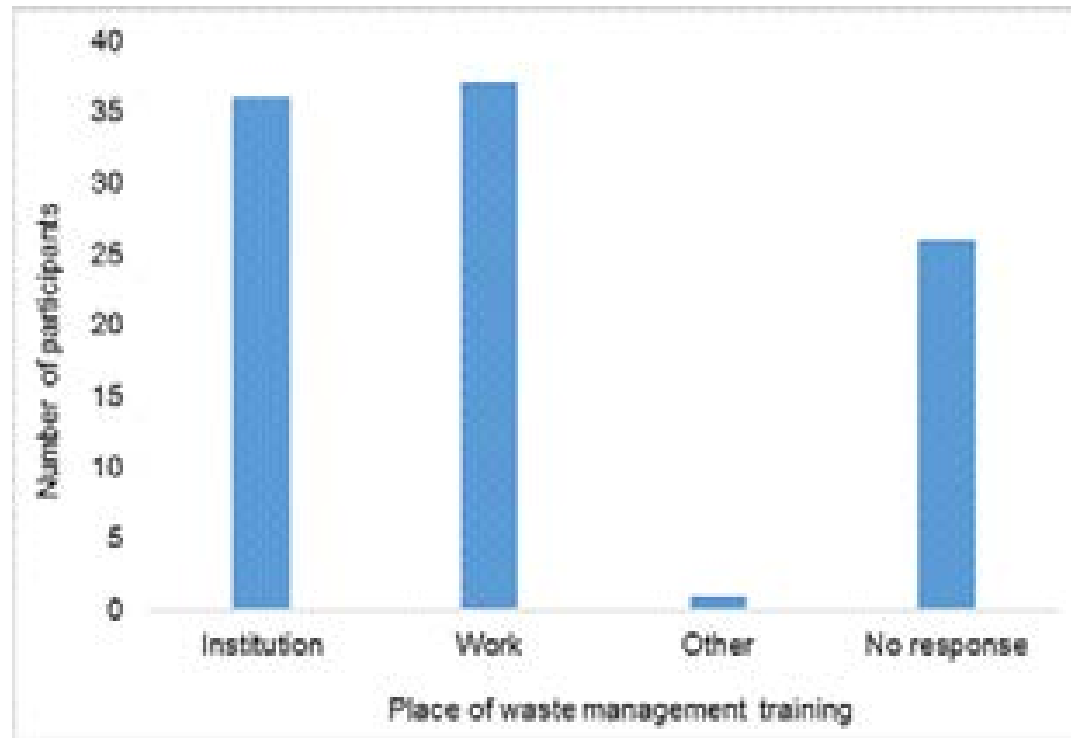

Figure 7. Places where participants received training on how waste should be disposed at the hospital 
The highest number of participants who had received training on health care waste management was the cleaning staff $(90.4 \%)$ with $85.7 \%$ having received training on health care waste management from work while only
$50.0 \%$ of the assistant nurses had received training on healthcare waste management (Figure 8). The highest number of doctors $(34.8 \%)$ had received training on health care waste management from institutions.

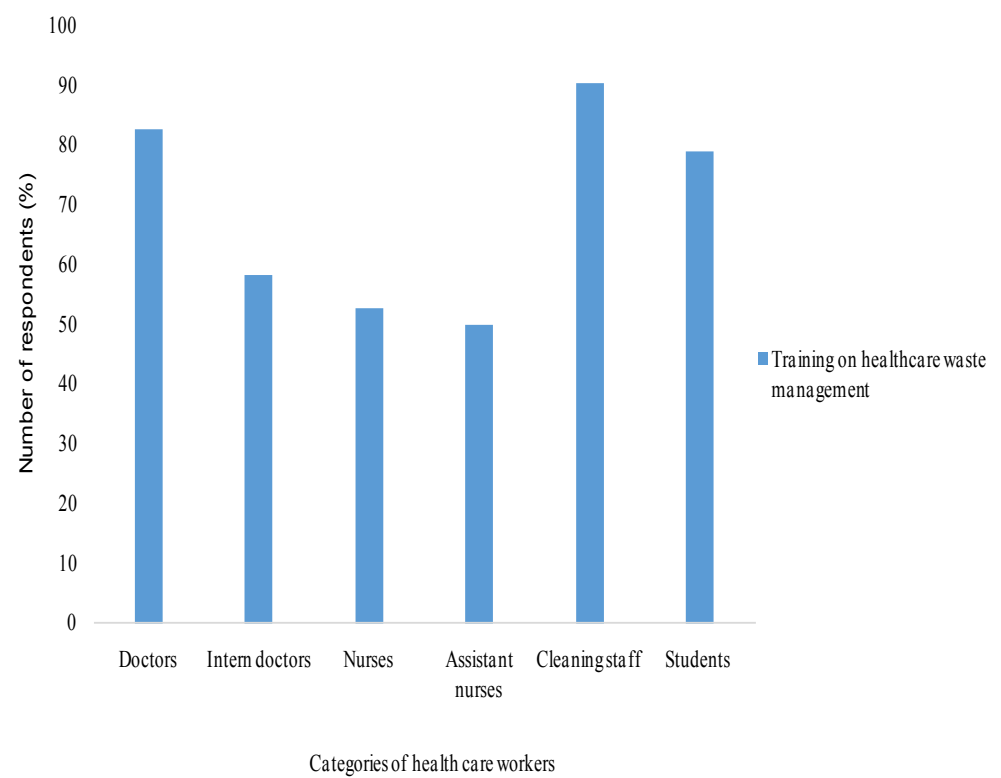

Figure 8. The different categories of participants who had received training on health care waste management.

The majority of the sixth year medical students $(84.2 \%)$ followed by medical doctors $(82.6 \%)$ had knowledge on the health care waste policy / legislation while nurses showed the lowest number $(55.9 \%)$ of participants with knowledge on the health care waste policy / legislation (Figure 9). 


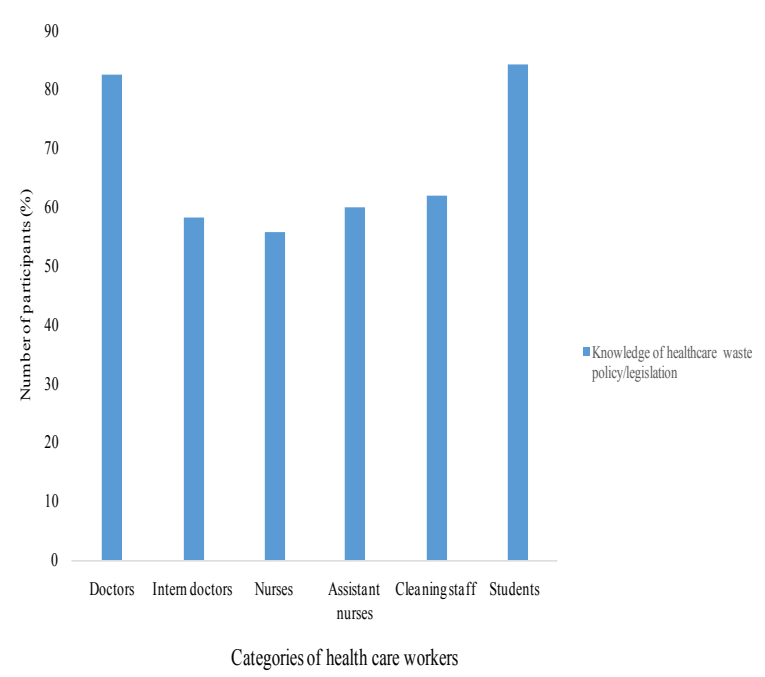

Figure 9. Number of participants with knowledge on healthcare waste policy / legislation.

The knowledge and the practices of the participants regarding handling of the healthcare waste is shown in Table 1. More participants (64\%) knew about the policies / legislations / guidelines on waste management compared to $36 \%$ who did not know about any policies or legislations or guidelines on waste management. Ninety percent $(90.0 \%)$ and eighty one percent $(81.0 \%)$ of the participants knew the proper colour coding for waste and the signs of each waste bin at the hospital respectively whereas only $10.0 \%$ and $19.0 \%$ did not know about the proper colour coding for waste bins and the signs of each waste bin at the hospital. The participants who knew about segregation of waste were $92.0 \%$, storage of waste $(70.0 \%)$, presence of different waste bins for different healthcare waste $(92.0 \%)$ and $48.0 \%$ of the participants knew where healthcare waste ends.

Table 1. Knowledge and practices of the respondents regarding hospital waste management.

\begin{tabular}{|lccc|}
\hline Knowledge of respondents on: & \multicolumn{3}{c}{ \% of Respondents } \\
& Yes & No & No response \\
\hline Policy/ legislation / guidelines on waste management & 64 & 36 & 0 \\
Proper colour coding for waste & 90 & 10 & 0 \\
Segregation of waste & 92 & 8 & 0 \\
Storage of waste & 70 & 29 & 1 \\
How waste is disposed / where waste ends & 48 & 46 & 6 \\
Signs of each waste bin in hospital & 81 & 19 & 0 \\
Risks associated with exposure to waste & 82 & 18 & 0 \\
Presence of different waste bins for different types of waste & 92 & 2 & 0 \\
Recapping of needles before disposal & 20 & 63 & 17 \\
Use of correct bins when disposing needles & 74 & 11 & 15 \\
Previous exposure to any risk / health hazard when dealing with & 30 & 70 & 0 \\
hospital waste & & & \\
\hline
\end{tabular}

Even though $82.0 \%$ of the participants knew about the risks which were associated with the exposure only $20.0 \%$ of the participants re-capped the needles after use before disposing them while $63.0 \%$ did not cap the used nee- dles before disposal. About $17.0 \%$ of the participants did not indicate whether they re-capped or did not re-cap the needles after use and before disposal. 
Even though $58.3 \%$ of the intern doctors and $52.9 \%$ of the sixth year medical students had stated that they had received training on healthcare waste management as shown in Table 2 , the highest number of intern doctors $(91.7 \%)$ and sixth year medical students $(89.5 \%)$ did not re-cap the needles after use and before disposal while the least number of doctors $(60.9 \%)$ did not re-cap the needles.

Seventy four percent $(74.0 \%)$ of the participants used the correct bins for disposing the needles compared to $11.0 \%$ of the participants who did not use the correct bins. The highest number of doctors $(97.0 \%)$ and sixth year medical students $(94.7 \%)$ indicated that they used the cor- rect and separate bins for disposing off healthcare waste followed by nurses $(82.4 \%$ ) and assistant nurses (80.0\%) while the least number of intern doctors used the correct and separate bins for healthcare waste (Table 2).

As shown in Table 2, even though the majority of the intern doctors did not re-cap the needles after use and before disposal, the lowest number of them had been exposed to needle pricks. Most of the nurses (64\%) had been exposed to needle pricks followed by doctors with only $20.0 \%$ of them having been exposed to needle pricks while none of the assistant nurses, cleaning staff and sixth year medical students had been exposed to needle pricks.

Table 2. The responses of the participants in relation to the demographic information.

\begin{tabular}{|c|c|c|c|c|c|c|c|c|c|c|c|c|c|c|c|c|c|c|}
\hline $\begin{array}{l}\frac{0}{n} \\
\frac{0}{3} \\
\frac{0}{0} \\
0 \\
0\end{array}$ & 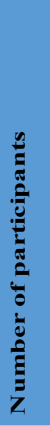 & 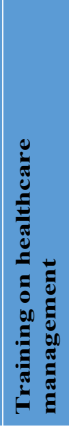 & 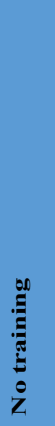 & 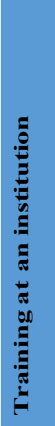 & 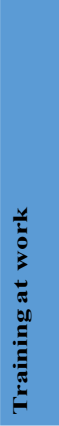 & 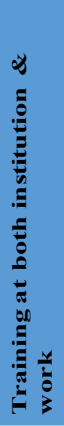 & 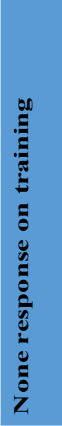 & 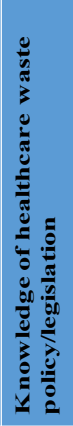 & 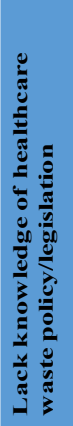 & 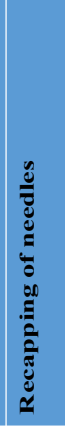 & 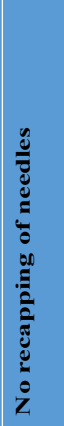 & 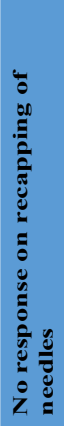 & 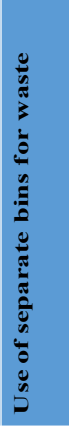 & $\begin{array}{l}0 \\
\vdots \\
\vdots \\
\vdots \\
\vdots \\
\vdots \\
0 \\
\vdots \\
0 \\
0 \\
\vdots \\
\vdots \\
0 \\
0 \\
\vdots \\
\vdots \\
0 \\
0 \\
\vdots \\
z \\
z\end{array}$ & 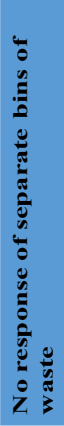 & 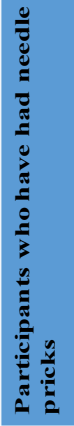 & 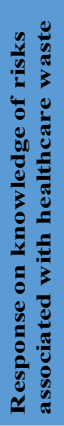 & 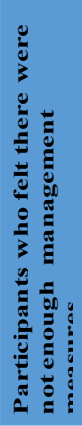 \\
\hline Doctors & 24 & 82.6 & 17.4 & 34.8 & 4.3 & 39.1 & 21.7 & 82.6 & 17.4 & 43.5 & 60.9 & 0 & 97.0 & 13 & 0 & 20.0 & 100 & 4.8 \\
\hline Intern doctors & 13 & 58.3 & 41.7 & 25.0 & 0 & 33.3 & 41.2 & 58.3 & 41.7 & 8.3 & 91.7 & 0 & 66.7 & 33.3 & 0 & 16.0 & 100 & 4.8 \\
\hline Nurses & 35 & 52.9 & 47.1 & 32.4 & 20.6 & 2.9 & 44.1 & 55.9 & 44.1 & 23.5 & 76.5 & 0 & 82.4 & 17.6 & 0 & 64.0 & 33.9 & 71.4 \\
\hline Assistant nurses & 12 & 50.0 & 50.0 & 20.0 & 0 & 30.0 & 50.0 & 60.0 & 40.0 & 20.0 & 80.0 & 0 & 80.0 & 20.0 & 0 & 0 & 60.0 & 0 \\
\hline Cleaning staff & 22 & 90.4 & 9.6 & 4.8 & 85.7 & 4.8 & 4.8 & 61.9 & 38.1 & 0 & 0 & 100 & 0 & 0 & 100 & 0 & 20.5 & 4.8 \\
\hline Students & 20 & 78.9 & 21.1 & 31.6 & 42.1 & 5.3 & 21.1 & 84.2 & 15.8 & 10.5 & 89.5 & 0 & 94.7 & 5.3 & 0 & 0 & 70.0 & 9.5 \\
\hline
\end{tabular}

The responses of the healthcare workers on the types of risks which they could be exposed to when dealing with healthcare waste and the type of risks which the participants had been exposed to while dealing with healthcare waste are shown in Figures 10 and 11 respectively. The majority of the participants $(49.0 \%)$ mentioned infections as the most common type of risk they could be exposed to when dealing with waste while $18.0 \%$ did not respond if they knew of any risks (Figure 10). 


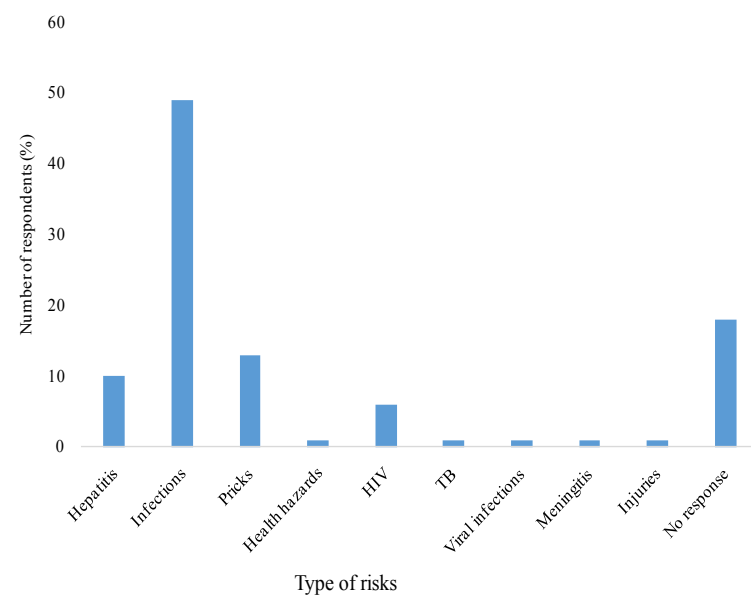

Figure 10. Responses on the types of risks the healthcare workers can be exposed to when dealing with waste.

Only $30.0 \%$ of the participants had had previous exposure to the risks / hazards when dealing with hospital waste compared to $70 \%$ who had not had prior exposure. As shown in Figure 11, 20.0\% of the participants had been pricked with needles followed by $7.0 \%$ who had been exposed to infections while 3.0\% had come into contact with blood when dealing with healthcare waste.

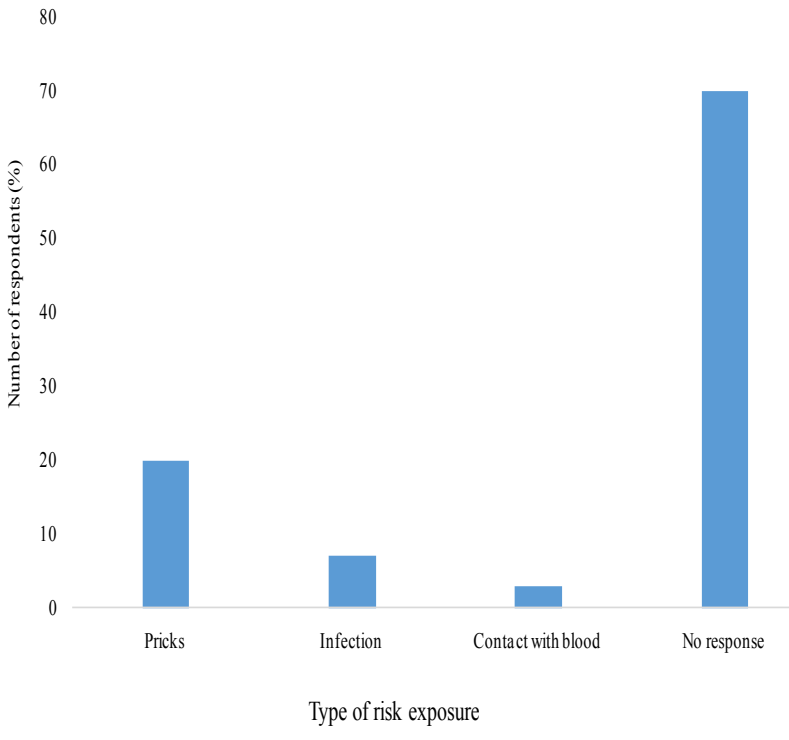

Figure 11. Type of risks the participants have been exposed to at the hospital.

Table 3 shows that even though the majority of the participants $(49.2 \%)$ did not recap the needles after use and before disposal they however used the correct bins for disposing and separating needles while a smaller number of the participants $(15.0 \%)$ recapped the needles after use and used the correct and separate bins for disposing needles. 
Table 3. Responses of the participants on the practices which are associated with healthcare waste.

\begin{tabular}{|l|c|}
\hline Responses & $\begin{array}{l}\text { Percentage of } \\
\text { participants } \\
(\%)\end{array}$ \\
\hline Recapping of needles and use of correct bins for the needles & 15 \\
No recapping of the needles and use of correct bins for needles & 49.2 \\
No recapping and no use of correct bins & 7.5 \\
No recapping but knowledge on risks associated with waste & 44.2 \\
No training on healthcare waste management and no separation of waste & 10.1 \\
Training on waste management and no knowledge of signs for bins & 33.3 \\
Had training on healthcare waste management and no separation of waste & 9.2 \\
\hline
\end{tabular}

A smaller proportion of the participants $(7.5 \%)$ did not recap the needles nor use the correct and separate bins for disposal. Irrespective of the participants $(44.2 \%)$ having knowledge about the risks which are associated with healthcare waste they still did not recap the needles after use and before disposal (Table 3).

Some of the participants $(33.3 \%)$ did not have knowledge on the different signs on healthcare waste bins irrespective of them having received training on healthcare waste management while a smaller proportion of the partic- ipants $(9.2 \%)$ who did not separate waste had received training on healthcare waste management.

Figure 12 shows the responses on whether there were enough management practices or measures being enforced with regards to the healthcare waste. The majority $(82 \%)$ of the participants felt that there were enough management practices or measures being enforced with regards to the healthcare waste while only $17.0 \%$ of the participants indicated that there were not enough management measures being enforced regarding the healthcare waste.

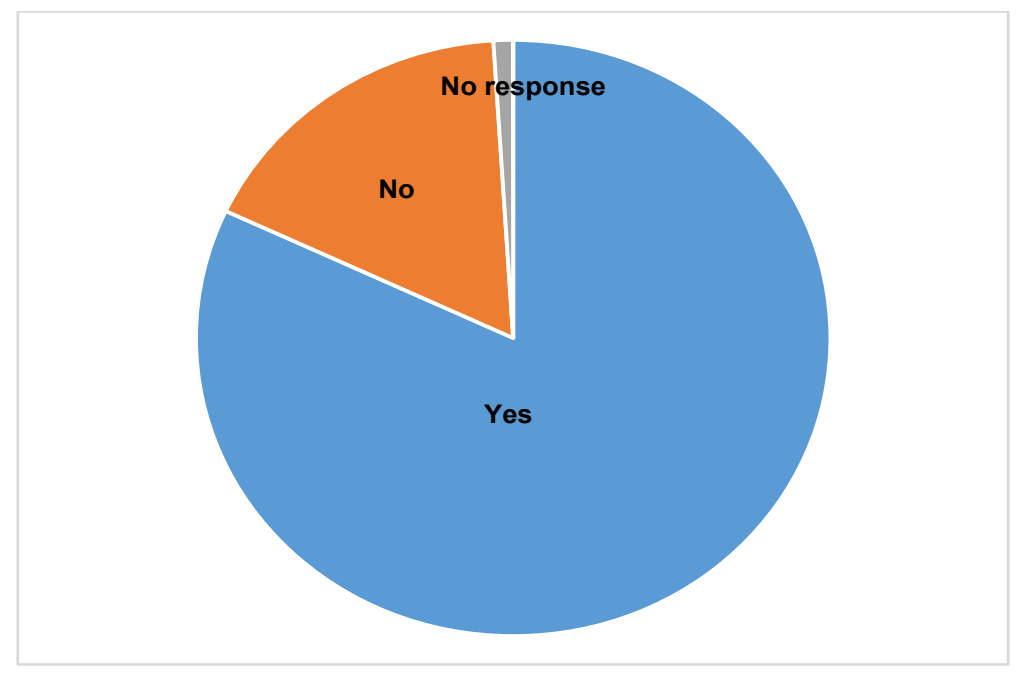

Figure 12. Responses on whether there were enough management practices or measures being enforced with regards to healthcare waste. 
The majority of the nurses $(71.4 \%)$ felt that there were not enough measures on health care waste management while the lowest number of doctors, intern doctors and cleaning staff all with $4.8 \%$ felt that there were not enough measures on health care waste management (Table 2). Some of the recommendations that were made by the participants were that there had to be more and enough waste bins for the disposal of the health care waste.

\section{Discussion}

The majority of the participants in the study were from the medical ward. These findings on the numbers of participants from different hospital wards are comparable with those of Yenesew et $\mathrm{al}^{16}$ where $22.3 \%$ of the participants were working at the medical ward. Most of the participants were in the middle age working group and the age distribution of the participants is comparable with the age distribution of Nagaraju et $\mathrm{al}^{17}$ where the majority of the participants were within the age group of 31-40 years. The findings of the gender distribution are in agreement with those of Sabageh et al. ${ }^{11}$ who also reported more females than males in their studies. The results of the present study however differ from those of Yenesew et $\mathrm{al}^{16}$ who reported a higher number of males at $58.0 \%$ than females. The findings of the professionals who took part in the study are in agreement with the studies by Alemayehu et $\mathrm{al}^{5}$ where the majority of the participants were nurses.

The knowledge, practices and attitudes of the nursing personnel at the hospitals with regards to the management of health care waste are crucial for the prevention and reduction of hazards related to health care waste. ${ }^{1}$ However, the findings of the present study are not comparable with those of Anand et al. ${ }^{18}$ who recorded more doctors taking part in the study. In the present study and in Enwere and Diwe ${ }^{19}$, the least number of the participants were the laboratory technicians or laboratory scientists. The results of the participants who had received training on how wastes should be disposed at the hospital are not in agreement with those of Abah and Obahimain ${ }^{20}$ which only had $11.5 \%$ of the participants who had been trained on health care waste management.

The findings of higher numbers of the participants having received training on how waste should be disposed in the the present study are not comparable with those of Malini and Bala ${ }^{21}$ where almost $50.0 \%$ of the health care workers had not received any form of training in biomedical waste management. These results are also not in agreement with those in Sharma et al. ${ }^{22}$ where about $36.0 \%$ of the nurses were found to have extremely poor knowledge about the health care waste management as found also in Bansal et al. ${ }^{23}$.

Training on health care waste management can contribute to better handling of health care waste and a reduction in the detrimental effects of the hazardous health care waste on the patients, health care workers and the environment. The detrimental impacts of health care waste can be minimised if the level of education and training on health care waste management is increased. ${ }^{24,25}$ Training of all the health care workers including the cleaning staff is crucial for the effective and appropriate management of health care / biomedical waste. ${ }^{26}$ According to Sabageh et al. ${ }^{11}$, participants who have received training on health care waste management are more likely to know about health care waste management better than those who had not received any training. Training on health care waste is significantly associated with the perceptions of risks of health care workers towards health care waste. ${ }^{16}$

The findings of more cleaning staff having received training on health care waste management from work as shown in the present study might have been due to compulsory training so that they are protected from the hazardous nature of the health care waste which they come into contact with on a daily basis when they clean up at the hospital. This should be expected since almost all the cleaning staff had not received any formal education from institutions of higher learning like the doctors and nurses.

The results of the number of health care workers who had knowledge on the health care waste management in the present study are not comparable with those in Bala and $\mathrm{Narwal}^{27}$ who reported that $60.0 \%$ of the participants had no knowledge on any legislation on the health care waste. Pandit et al..$^{28}$ and Saini et al. ${ }^{25}$ reported on much lower knowledge of the biomedical waste by the sanitary workers whereas in the present study there were higher numbers of cleaning staff who had knowledge on legislation and policy associated with healthcare waste management. In a study by Kagonji and Manyele ${ }^{29}$, the existence of crucial documents such as legislations, manuals and policies in all the surveyed hospitals was below $40.0 \%$ indicating that health care workers were not guided by any 
management tool which led to operating by intutuition hence leading to poor management of health care waste. The results on the knowledge and practises of participants regarding handling of the health care wastes are not comparable with findings of Debere et al. ${ }^{30}$ where none of the hospitals in the study reported using the colour coding system and there was also no segregation of health care waste. With respect to the knowledge on the separation and segregation of health care waste, the findings in the present study are in agreement with Enwere and Diwe ${ }^{19}$ who reported that there was a maximum number of health care workers who followed proper disposal of health care waste into specified waste containers. The findings in the present study also differ with those of Rudraswamy et al. ${ }^{2}$ who reported that $82.6 \%$ of the participants indicated that it was necessary to separate waste into different categories where it originated.

Inadequate separation of health care waste could lead to insufficient treatement and disposal of health care waste which could then result in risks to the health care workers, the environment and the human health in general. ${ }^{5}$ With regards to the number of participants who knew about the risks which are associated with the exposure of waste the results are not comparable with the results by Enerwe and Diwe ${ }^{19}$ where $44.8 \%$ of the participants recapped the needles after use.

An increased awareness of the risks and diseases associated with health care waste can result in an improvement on the precautionary measures which the health care workers may take when they are dealing with health care waste. ${ }^{30}$ The findings in the present study of all the doctors, intern doctors and sixth year medical students having knowledge on infectious diseases which are associated with lack of proper waste management in the present study, are in agreement with the results in Malini and $\mathrm{Bala}^{21}$ and Ramokate and $\mathrm{Basu}^{6}$ where all the categories of the health care workers had good knowledge about the infectious diseases associated with improper management of health care waste. The results on the lack of responses on the risks by the nurses and the cleaning staff are in agreement with the results of Kagonji and Manye$\mathrm{le}^{29}$ where there was a low awareness among health care workers on the risks and diseases associated with poor management of health care waste.

The findings on segregation of waste in the present study agree with those in Ferreira and Teixeira ${ }^{4}$; Malini and
$\mathrm{Bala}^{21}$ where there was insufficient knowledge on the separation of health care waste by the health care workers. In a study by Bassey et al. ${ }^{31}$ the waste segregation at the selected hospitals in Abuja was found to be zero while in Ngwuluka et al. ${ }^{32}$ none of the 6 major hospitals were found to practise the segregation of waste. It has also been reported that there is lack of adequate separation of health care waste in other developing countries such as in Pakistan ${ }^{33}$, Iran ${ }^{34}$ and in Bangladesh ${ }^{35}$. According to Mostafa et al. ${ }^{36}$ it has also been reported that in many studies in other developing countries the knowledge on the segregation of health care waste and collection of health care waste in colour coded containers was lacking. The effective separation of the health care waste from where it is generated and the use of appropriate containers of health care waste is the most relevant way of protection against the harmful effects of the needles and sharps Blenkharn and Odd ${ }^{37}$. The transmission of the diseases from the used sharps and needles to the patients and the health care workers requires critical attention during the handling and managing of the health care waste comprising sharps and needles. ${ }^{38}$

These findings on high exposure of the nurses to needle pricks are not comparable to those of Ferreira and Teixe$\mathrm{ra}^{4}$ where the number of doctors who had been exposed to pricks was much higher than the number of nurses who had also been exposed to pricks. However, the results are in agreement with those of Stein et al. ${ }^{39}$ where only $37.0 \%$ of the doctors and nurses reported to have never suffered any injury from the needle pricks. Also in the present study none of the cleaning staff had mentioned exposure to pricks whereas in Ferreira and Teixera4 the housekeepers $(31.8 \%)$ had reported needle pricks. The results on numbers of needle pricks are also not comparable with those in Leigh et al. ${ }^{40}$ where the number of the nurses who had been exposed to pricks were much lower at $22.3 \%$.

Needle pricks and sharps can be accountable for the majority of the accidents and pose a major hazard and risks to the staff handling and transporting waste, workers in waste disposal facilities, scavengers and the public in general more especially children playing with health care waste or items in the waste outside the health care facilities. Exposure to needle pricks can be regarded as the most hazardous forms of risks since there can be exchange of the blood which might be infected with oth- 
er infections such as HIV aids. All health care workers should then be more careful when it comes to the handling and the disposal of the needles.

\section{Limitations}

Limitations in the current study were that only a few hospital wards were included in the study and the busy schedules of the health care workers (especially nurses) resulted in their reluctance to take part in the study. Failure of the previous researchers to report the findings back to the participants resulted in the discouraging of healthcare workers to complete the questionnaires. The workers who declined to take part in the study complained that questionnaires were usually left by researchers without clarification of all the questions hampering their capability to successfully complete the questionnaires. The questionnaires were only in English and this might have been a barrier to the cleaning staff to respond to all the questions with ease and understanding. Participants misinterpreted some of the questions resulting in those questions being discarded and not interpreted in the study.

Future research directions include similar studies being carried out in more wards at the same hospital for a better representation of the health care workers at the hospital. Other similar studies can be carried out at other health care facilities and also at private hospitals for comparative studies.

\section{Conclusion}

It can be concluded from the study that the majority of the participants who had post (12 years of) schooling level of education had received training on how health care waste is disposed, knew about policies and legislations regarding healthcare waste and the risks associated with health care waste. However, most of the participants did not practice a basic act of how health care waste should be handled which is the recapping of the needles after use and before disposal. Training of health care workers at work is crucial and can benefit both literate and illiterate health care workers. In addition to the provision of more waste bins which was recommended by the participants, management should provide education through regular workshops to staff on how hazardous waste especially blood infected sharps and needles should be handled. More posters should also be put up in all the departments and wards on handling and disposal of health care waste. Other similar studies should be carried out at other healthcare facilities such as private hospitals.

\section{Acknowledgements}

The authors would like to thank the staff at the Dr George Mukhari Hospital and the sixth year medical students at the Sefako Makgatho Health Sciences University for making time to complete the questionnaires. Funding for the project was made available through the Research Development Grant which was awarded to Dr Mugivhisa LL for the completion of the $\mathrm{PhD}$ research.

\section{Conflict of interest}

None declared.

\section{References}

1. Shivalli S, Sanklapur V. Healthcare waste management: Qualitative and quantitative appraisal of nurses in a Tertiary Care Hospitals of India. Hindawi Publishing Corporation. The Sci World J 2014. ID 935101.

2. Rudraswamy S, Sampath N, Doggalli N. Staff's attitude regarding healthcare waste management in the dental college hospitals of Bangalore city, India. Indian J Occup Environ Med 2012; 16(2): 75-78.

3. Joshi SC, Diwan V, Tamhankar AJ, Joshi R, Shah H, Sharma M, Kagonji IS, Manyele SV. Analysis of health workers' perceptions on medical waste management in Tanzanian hospitals. Eng 2016; (8): 445-459.

4. Ferreira V, Teixeira MR. Healthcare waste management practices and risk perceptions: Findings from hospitals in the Algarve region, Portugal. Waste Man 2010; 30: 2657-2663.

5. Alemayehu T, Worku A, Assefa N. Community risk perception on healthcare wastes in hospitals and health centres of Eastern Ethiopia. Sci J of Public Heal. 2015;3(1): 37-43.

6. Ramokate T, Basu D. Health care waste management at an academic hospital: Knowledge and practices of doctors and nurses. SAMJ 2009; 99(6).

7. Adegbita M, Nwafor S, Afon A, Abengude A, Bamise C. Assessment of dental waste management in a Nigerian tertiary hospital. Waste Manag 2010; 28: 769-77. 8. Health Professions Council of South Africa. 2008 Guidelines for good practice in the health care professions. Guidelines for the management of health care waste. Booklet 16.

9. Makhura RR, Matlala SF, Kekana, MP. Medical waste disposal at a hospital in Mpumalanga Province, South Africa: Implications for training of healthcare professionals. SAMJ (2016); 106(11).

10. Olaifa A, Govender RD, Joss AJ. Knowledge, attitudes and practices of healthcare workers about health- 
care waste management at a district hospital in KwaZulu-Natal, S Afr Fam Pract 2018; 60(5): 137-145, DOI: 10.1080/20786190.2018.1432137.

11. Sabageh AO, Adeomi AA, Odeoye OAA, Abodunrin OL, Oladimeji OJ., Oke FE. Perception and practices of healthcare workers in south western Nigeria towards Healthcare Waste Management. British J Med Health Res 2015; 2(8): ISSN: $2394-67$.

12. Mathur V, Dwivedi S, Hassan MA, Misra RP. Knowledge, attitude and practices of biomedical waste management among healthcare personnel: A cross-sectional study. Indian J Comm Med 2011; 36: 143-145.

13. Mugivhisa LL, Olowoyo JO. Growth and nutritional composition of Spinacia oleracea L. harvested from soil treated with urine in comparison with other organic and inorganic soil amendments. West African J of Appl Ecol 2016; 24(2): 19 -30.

14. www.health.gpg.gov.za/hospitals/Pages/ George-Mukhari-Academic.aspx).

15. Haider A, Amber A, Ammara S, Mahrukh KS, Aisha B. Knowledge, perception and attitude of common people towards solid waste management - A case study of Lahore, Pakistan. Int Res J Environ 2015 4(3): 100-107. 16. Yenesew MA, Moges HG, Woldeyohannes SM. A cross sectional study on factors associated with risk perception of healthcare workers toward healthcare waste management in health care facilities of Gondar Town, Northwest Ethiopia. Int J Infect Control 2012. Doi: 10.3396/ijic.v8i3.024.12.

17. Nagaraju B, Padmavathi G, Puranik D, Shantharaj M, Sampulatha S. A study to assess the knowledge and practice on bio-medical waste management among the health care providers working in PHCs of Bagepalli Taluk with the view to prepare informational booklet. Int J Med Biomed Res 2013; 2(1): 28-35.

18. Anand P, Jain, R, Dhyani, A. Knowledge, attitude and practice of biomedical waste management among health care personnel in a teaching institution in Haryana, India. Int J Res Med Sci 2016; 4(10): 4246-4250.

19. Enwere OO, Diwe KC. Knowledge, perception and practice of injection safety and healthcare waste management among teaching hospital staff in south east Nigeria: an intervention study. Pan African Medical Journal 2014. Open Access at: www.panafrican-med-journalISSN 1937-8688.

20. Abah S, Ohimain E. Healthcare waste management in Nigeria: A case study. I Public Heal Epidemiol 2011; 3: 99-110.
21. Malini A, Bala E. Knowledge, attitude and practice of biomedical waste management among health care personnel in a tertiary care hospital in Puducherry. Int J Biomed Res 2015; 6(3): 172-176. DOI:10.7439.

22. Sharmar A, Sharma V, Sharma S, Singh P. Awareness of biomedical waste management among health care personnel in Jaipur, India. Oral Health and Dent Manag 2013; 12(1): 32-40.

23. Bansal M, Mishra A, Gautam P, Changulani R, Srivastava D, Gour NS. Knowledge and awareness regarding biomedical waste management among employees of a tertiary care hospital. Indian J of Community Health 2013; 25(1): 86-88.

24. Singh H, Rehman R, Bumb SS. Management of biomedical waste: a review. Int J Dent Med Res 2014; 1(1): 14-20.

25. Saini S, Nagarajan SS, Sarma RK. Knowledge; Attitude and practices of bio-medical waste management amongst staff of a tertiary level hospital in India. J Acad Hosp Adm. 2005; 17:2.

26. Kishore J, Goel P, Sagar B, Joshi TK. Awareness about biomedical waste management and infection control among dentists of a teaching hospital in New Delhi, India. Indian J Dent Res 2000;11: 157-61.

27. Bala S, Narwal A. Awareness of bio-medical waste management among hospital and dental college and hospital employees. A Panoramic View of J Oral Health Comm Dent 2013; 7: 1-7.

28. Pandit NB, Mehta HK, Kartha GP, Choudhary SK. Management of bio-medical waste: Awareness and practices in a district of Gujarat. Indian J Public Health 2005; 49: 245-7.

29. Kagonji IS, Manyele SV. Analysis of health workers' perceptions on medical waste management in Tananian Hospitals. Eng 8: 2016; 445-459.

30. Debere, MK, Gelaye KA, Alamdo AG, Trifa ZM. Assessment of the health care waste generation rates and its management system in hospitals of Addis Ababa, Ethiopia, 2011. BMC Public Health 2013; 13:28.

31. Bassey BE, Benka-Coker MO, Aluyi HS. Characterisation and management of solid medical wastes in the Federal Capital Territory, Abuja Nigeria. Afr Health Sci 2006; 6(1): 58-63.

32. Ngwuluka N, Ochekpe N, Odumosu P, John SA. Waste management in healthcare establishments within Jos Metropolis Nigeria. Iran J Environ Health Sci Eng. 2009; 3(12): 459-65.

33. Kumar R, Samrongthong R, Shaikh BT. Knowl- 
edge, attitude and practices of health staff regarding infectious waste handling of tertiary care of health facilities at metropolitan city of Pakistan. J Ayub Med Coll Abbottabad 2013; 25 (1-2): 109-12.

34. Askrian M, Vakili M, Kabir G. Hospital waste management status in university hospitals of the Fars province, Iran. Int J Environ Heal R Journal 2004; 14: 295305.

35. Hassan MM, Ahmend SA, Rahman KA, Biswas TK. Pattern of medical waste management: existing scenario in Dhaka City, Bangladesh. BMC Public Health 2008; $8(36)$.

36. Mostafa G, Shazly M, Sherief W. Development of a waste management protocol based on assessment of knowledge and practice of healthcare personnel in surgical departments. Waste Manag 2007; 29(1): 430-439.

37. Blenkharn JI, Odd C. Sharps injuries in healthcare waste handlers. Ann. Occup Hyg 2008; 52(4): 281-286. 38. Allsopp M, Costner P, Johnston P. State of knowledge of the impacts of waste incinerators on human health. Environ Sci Pollution Res 2001; 8(2): 141-145. 39. Stein AD, Makarawo TP, Ahmad MF.A survey of doctors' and nurses' knowledge, attitudes and compliance with infection control guidelines in Birmingham teaching hospitals. J Hosp Infect 2003; 54: 68-73.

40. Leigh I, Wiatrowski W, Gillen M, Steenland N. Characteristics of persons and jobs with needlesticks injuries in a national data set. Am J Infect Control 2008;36: 414-420. 